BMJ Open

Respiratory

Research

\title{
Attitudes and access to lung volume reduction surgery for COPD: a survey by the British Thoracic Society
}

\author{
William McNulty, Simon Jordan, Nicholas S Hopkinson on behalf of The British \\ Thoracic Society
}

To cite: McNulty W, Jordan S, Hopkinson NS et al. Attitudes and access to lung volume reduction surgery for COPD: a survey by the British Thoracic Society. BMJ Open Resp Res 2014;1:e000023.

doi:10.1136/bmjresp-2014000023

Received 27 January 2014 Revised 3 April 2014 Accepted 7 April 2014

\section{CrossMark}

NIHR Respiratory Disease, Biomedical Research Unit at the Royal Brompton and Harefield NHS Foundation Trust and Imperial College London, London, UK

Correspondence to Dr Nicholas S Hopkinson; n.hopkinson@ic.ac.uk

\section{ABSTRACT}

Objective: Lung volume reduction surgery for emphysema leads to improved survival in appropriately selected individuals, and it is therefore recommended in national and international guidelines for this group of patients. Despite this, fewer than 100 patients undergo the procedure each year in the UK. Our objective was to establish whether this reflects concerns about morbidity and mortality or difficulties in the referral pathway.

Design and setting: We conducted a survey of members of the British Thoracic Society by email to investigate this in the second half of 2013. The survey included questions about access to investigations, the indications for lung volume reduction surgery (LVRS), whether a multidisciplinary meeting discussed eligibility of patients for LVRS and what the morbidity and mortality associated with the procedure was.

Results: There were 65 responses, $82 \%$ from respiratory physicians. Roughly half of the respondents were either unsure about the risks of death or prolonged (>30 days) hospital stay involved or significantly over-estimated them. In total, $70 \%$ did not have a specific multidisciplinary team to discuss the management of patients with advanced chronic obstructive pulmonary disease (COPD). There was no consensus as to which patients with COPD should undergo a CT scan to evaluate them for possible surgery.

Conclusions: Patients with COPD require a systematic and multidisciplinary approach to assessment for LVRS and these survey data suggest that work is needed to deliver this evidence-based therapy in a consistent and comprehensive way across the UK.

\section{BACKGROUND}

Chronic obstructive pulmonary disease (COPD) is a major cause of disability and mortality in the UK and is now the third most frequent cause of death worldwide ${ }^{12}$ as a consequence of the ongoing epidemic of tobacco addiction. ${ }^{3}$ The pathological processes involved, destruction of small airways and lung parenchyma as well as narrowing of

\section{KEY MESSAGES}

The paper describes a survey sent to all members of the British Thoracic Society to find out about attitudes and knowledge around lung volume reduction surgery, showing that there is uncertainty and overestimation of the risks associated with the procedure.

- The response rate was low, but that itself may reflect a lack of engagement with lung volume reduction surgery as a treatment for people with emphysema.

- Although the low response rate impacts on the precision of some of the estimates the responders are likely to have been better informed and results from a larger group are unlikely to have presented a 'better' picture.

larger airways, are poorly responsive to medical therapies and many patients remain severely disabled despite optimum medical therapy. ${ }^{4}$ Only a handful of treatments including smoking cessation, long-term oxygen therapy in selected patients and lung volume reduction surgery (LVRS) have been shown to improve prognosis. ${ }^{5-8}$

LVRS was described as a palliative treatment for emphysema by Brantigan and Muller in $1957 .^{9}$ The aim of LVRS is to resect the most emphysematous portion of the lung. This allows healthier, less compliant areas to be ventilated more effectively, reduces operating lung volumes and thus improves chest wall and respiratory muscle mechanics. In the US National Emphysema Treatment Trial (NETT), ${ }^{5}{ }^{6}$ patients with an upper lobe predominant pattern of emphysema and a low preoperative exercise capacity gained the maximum benefit and had increased survival, which long-term economic analysis suggests is achieved at an acceptable cost per quality-adjusted life year. ${ }^{10}$ The NETT study also identified a group of patients with an excess risk of surgical mortality: those with 
a forced expiratory volume $1 \mathrm{~s}\left(\mathrm{FEV}_{1}\right)<20 \%$ predicted and either homogeneous disease or a carbon monoxide transfer factor $<20 \%$ predicted. The mortality rate for patients excluding this high-risk group was 5.2\% at 90 days. In the NETT trial, complications included major respiratory or cardiac complication in $29.8 \%$ and $20 \%$ of patients, respectively. At 1 month, $28.1 \%$ of patients were still hospitalised or in a long-term care facility. However, audit of current practice suggests that mortality and morbidity are significantly lower. ${ }^{11}$

Data from the UK Society of Cardiothoracic Surgery (SCTS) register, http://www.scts.org/professionals/audit_ outcomes.aspx show that only 96 procedures in 2009-2010 and 90 in 2010-2011 were recorded. The likely pool of eligible patients is significantly larger than this ${ }^{12}$ and there is therefore concern that patients who may benefit are not being considered for treatment. Some authors have suggested that physicians are deterred from referral as LVRS is perceived as too complicated with limited patient benefit and a substantial risk of complications. ${ }^{5}$ To improve understanding of the obstacles limiting provision of LVRS to suitable patients with COPD, we undertook a survey of members of the British Thoracic Society (BTS).

\section{METHODS}

A survey including questions about clinicians' attitudes to and knowledge of LVRS was designed in collaboration with the British Thoracic Society Professional and Organisational Standards of Care Committee of the BTS. The survey is available in the online supplementary material. The survey was completed electronically and a link to complete it sent out to 2498 BTS members in the monthly e-newsletter on two occasions.

\section{RESULTS}

There were 65 respondents to the questionnaire with replies from all UK nations and 13 different regions in total. A total of $82 \%$ were consultant physicians and $11 \%$ specialist trainees in respiratory medicine (table 1). The remainder comprised two respiratory nurses, one thoracic surgeon, one physiotherapist and one clinical physiologist. Twenty two (34\%) identified themselves as the COPD lead for their organisation.

\section{Indications for LVRS, morbidity and mortality}

In identifying which patients would derive the most benefit from LVRS, $60 \%$ of respondents correctly identified those with heterogeneous emphysema and a low exercise capacity. Estimates for a 30-day mortality were $0-5 \%$ in $52 \%$ of respondents, $21 \%$ overestimated this and $27 \%$ did not know. A third of the respondents thought that more than $10 \%$ of patients would be in hospital 1 month postprocedure and $28 \%$ were unsure.

\section{Process issues around LVRS}

Roughly half of the respondents $(52 \%)$ worked in a teaching hospital and the remainder within district general hospitals. A lung volume reduction service was available in $27 \%$ of respondents' hospitals and a further $41 \%$ had a centre within 20 miles. When asked about the referral of patients for LVRS, $68 \%$ had referred patients for LVRS in the past 12 months and $97 \%$ said that they knew how to make a referral for LVRS. The number of referrals by each respondent is listed in table 2. The majority of respondents $(70 \%)$ did not have a multidisciplinary team (MDT) to discuss such cases within their hospital, although 54\% answered that an MDT was available in their local referral centre. Of those respondents who worked in a referral centre, $65 \%$ had an MDT to discuss LVRS cases. Bronchoscopic lung volume reduction was available in the hospital of $13 \%$ of respondents with a further $21 \%$ planning to offer a service in the future.

Access to investigations for the work-up for LVRS is detailed in table 2. When asked whether a CT scan was indicated for patients with COPD with an $\mathrm{FEV}_{1}<50 \%$ predicted, $32 \%$ agreed or strongly agreed while $44 \%$ disagreed or strongly disagreed.

In the free text section, 18 respondents left comments. One surgeon felt that there were likely to be many more patients who may benefit but were not being recognised as potential candidates. Two physicians commented that there was a misconception regarding the benefits and risks of surgery. Another remarked that referral criteria, particularly regarding exercise capacity, were not always clear. One physician added that determining emphysema heterogeneity was rarely performed at their centre. Access to pulmonary rehabilitation was mentioned by two respondents. Three physicians commented that they were increasingly opting for bronchoscopic procedures, while another felt that there was insufficient evidence for their use.

\section{DISCUSSION}

The main findings from the present survey are, first, that there are significant information needs around the indications for LVRS and the accompanying risks of morbidity and mortality. Second, there is a lack of systematic structures to evaluate patients and, third, there is a lack of consensus about the best approach for screening individuals to identify potential candidates for LVRS.

LVRS for selected patients is recommended in national and international guidelines for the management of COPD. ${ }^{1314}$ This survey suggests that the majority of those surveyed know how to refer patients for LVRS and had done so within the last year. A significant proportion of respondents were clinical leads for COPD in their organisation and the majority had referred a patient for potential LVRS in the last year, suggesting that the respondents were likely to represent the more engaged clinicians in this area. However, survey responses suggest that published historical data from the late 1990s and early 21st century inform many individuals' assessment of risk. In current surgical practice with largely unilateral, thoracoscopic 


\section{Table 1 Summary of question results}

\begin{tabular}{|c|c|c|}
\hline & Total & Percentage \\
\hline \multicolumn{3}{|l|}{ What is your role? $(n=65)$} \\
\hline Consultant physician & 53 & 82 \\
\hline Consultant surgeon & 1 & 2 \\
\hline Specialty trainee & 7 & 11 \\
\hline Specialty trainee (other specialty) & 0 & 0 \\
\hline Foundation trainee & 0 & 0 \\
\hline Physiotherapist & 1 & 2 \\
\hline Lung physiologist & 1 & 2 \\
\hline Respiratory nurse & 2 & 3 \\
\hline \multicolumn{3}{|l|}{ Where is your main place of work? $(n=63)$} \\
\hline Secondary care-DGH & 30 & 48 \\
\hline Secondary care-teaching hospital & 33 & 52 \\
\hline \multicolumn{3}{|l|}{ Are you the COPD lead for your organisation? $(n=64)$} \\
\hline Yes & 22 & 34 \\
\hline No & 42 & 66 \\
\hline \multicolumn{3}{|c|}{ I have referred a patient for consideration of LVRS within the past 12 months ( $n=63$ ) } \\
\hline Yes & 43 & 68 \\
\hline No & 18 & 29 \\
\hline Not applicable & 2 & 3 \\
\hline \multicolumn{3}{|c|}{ If 'yes', approximately how many patients have you referred for LVRS in the past 12 months? $(n=45)$} \\
\hline $1-3$ & 35 & 78 \\
\hline $4-6$ & 6 & 13 \\
\hline More than 6 & 3 & 7 \\
\hline Not known & 1 & 2 \\
\hline \multicolumn{3}{|l|}{ I know how to refer patients for LVRS $(n=63)$} \\
\hline Yes & 61 & 97 \\
\hline No & 1 & 2 \\
\hline Not sure & 1 & 2 \\
\hline \multicolumn{3}{|c|}{ Do you have a specific MDT meeting to discuss the management of patients with advanced COPD? $(n=64)$} \\
\hline Yes & 18 & 28 \\
\hline No & 45 & 70 \\
\hline Not known & 0 & 0 \\
\hline Not applicable & 1 & 2 \\
\hline \multicolumn{3}{|c|}{ Does the thoracic surgical service you use have an MDT to discuss potential LVRS patients? $(n=63)$} \\
\hline Yes & 34 & 54 \\
\hline No & 14 & 22 \\
\hline Not known & 14 & 22 \\
\hline Not applicable & 1 & 2 \\
\hline \multicolumn{3}{|c|}{ How far away is the nearest LVRS service? (estimate) $(n=64)$} \\
\hline On site & 17 & 27 \\
\hline Less than 20 miles away & 26 & 41 \\
\hline Between 20 and 40 miles away & 8 & 12 \\
\hline Over 40 miles away & 12 & 19 \\
\hline Not known & 1 & 2 \\
\hline \multicolumn{3}{|c|}{ What do you estimate the 30 day mortality is following LVRS? $(n=63)(\%)$} \\
\hline $0-5$ & 33 & 52 \\
\hline $6-10$ & 9 & 14 \\
\hline $11-15$ & 1 & 2 \\
\hline$>15$ & 3 & 5 \\
\hline Not known & 17 & 27 \\
\hline \multicolumn{3}{|c|}{ What proportion of patients do you think would still be in hospital 30 days following LVRS? $(n=65)(\%)$} \\
\hline $0-4$ & 10 & 16 \\
\hline $5-9$ & 17 & 27 \\
\hline $10-15$ & 14 & 22 \\
\hline$>15$ & 6 & 9 \\
\hline Not known & 18 & 28 \\
\hline \multicolumn{3}{|c|}{ Which group of patients derive the most benefit from LVRS? $(n=65)$} \\
\hline Homogeneous emphysema, low exercise capacity & 10 & 15 \\
\hline
\end{tabular}


Table 1 Continued

\begin{tabular}{|c|c|c|}
\hline & Total & Percentage \\
\hline Homogeneous emphysema, high exercise capacity & 3 & 5 \\
\hline Heterogeneous emphysema, low exercise capacity & 41 & 63 \\
\hline Heterogeneous emphysema, high exercise capacity & 12 & 18 \\
\hline Not known & 3 & 3 \\
\hline \multicolumn{3}{|c|}{$\begin{array}{l}\text { CT scanning may be indicated for haemoptysis, recurrent exacerbations or to investigate hypoxia, looking at pulmonary } \\
\text { arteries or for interstitial fibrosis. Excluding these specific indications, do you think a CT of the thorax is indicated routinely in } \\
\text { patients with an } \mathrm{FEV}_{1}<50 \% \text { predicted? }(n=65)\end{array}$} \\
\hline Strongly agree & 4 & 6 \\
\hline Agree & 17 & 26 \\
\hline Neither agree nor disagree & 15 & 23 \\
\hline Disagree & 25 & 38 \\
\hline Strongly disagree & 4 & 6 \\
\hline \multicolumn{3}{|c|}{$\begin{array}{l}\text { Various bronchoscopic techniques which are intended for lung volume reduction are being developed-which option best } \\
\text { applies to your organisation? }(n=63)\end{array}$} \\
\hline We currently offer bronchoscopic lung volume reduction & 8 & 13 \\
\hline We intend to offer bronchoscopic lung volume reduction & 13 & 21 \\
\hline We have no plans to offer bronchoscopic lung volume reduction & 37 & 59 \\
\hline Not applicable & 3 & 5 \\
\hline Not known & 2 & 3 \\
\hline
\end{tabular}

approaches for LVRS, the morbidity and mortality are significantly lower than reported in the NETT trial ${ }^{5}$ with no deaths within 90 days and only $6 \%$ of patients in hospital at 30 days reported in one recent series. ${ }^{11}$

Most hospitals appear to have easy access to appropriate investigations, but there was no consensus on when a CT of the thorax is indicated. It has been proposed that a routine assessment of the pattern of emphysema by CT scan, as well as gas transfer measurement, should be considered in all patients with COPD with Medical Research Council dyspnoea scores of 4 or 5 and an $\mathrm{FEV}_{1}<50 \%$, unless there are obvious comorbidities precluding surgery, with review by an MDT including chest physicians, surgeons and radiologists, as is already the case for the management of lung cancer. ${ }^{15}$ Clearly, this requires decisions about the appropriate allocation of resources to ensure best value. The cost per quality-adjusted life year of LVRS in the NETT study in upper lobe predominant emphysema was estimated to be $\$ 48000$ for low exercise capacity and $\$ 40000$ for high exercise capacity patients at 10 years. ${ }^{10}$ The true cost in current practice is likely to be considerably lower than this as the costs are driven by early surgical morbidity and mortality, which are lower now. ${ }^{11} 16$
The response rate to the survey was low, which impacts on the precision of the findings. We have no data as to the reasons for non-response, and can therefore only speculate. However, as a self-selecting group, respondents may be expected to have been more interested in LVRS, so it is unlikely that responses from a larger sample would have produced 'better' results. Clearly, people may have been too busy to respond, but non-response itself may also represent a general lack of engagement with lung volume reduction strategies in COPD. The overestimation of mortality risk by half of the respondents and the overestimation of hospital stay by $60 \%$ of the respondents may contribute to this disengagement. A further consequence of this is that low referral rates have made the development of bronchoscopic approaches, ${ }^{17-20}$ intended to deliver lung volume reduction either more safely or in different emphysema phenotypes, ${ }^{21}{ }^{22}$ more difficult.

Lung volume reduction has a strong evidence base in appropriately selected patients with COPD where, unlike current pharmacotherapy, it can modify the natural history of the disease. ${ }^{5} 1923$ The survey confirms that work is needed to ensure that clinicians are aware of the risks and benefits associated with the technique in modern

Table 2 Access to investigations for lung volume reduction surgery

\begin{tabular}{|c|c|c|c|c|c|c|c|c|}
\hline & \multicolumn{2}{|c|}{ Easy to access } & \multicolumn{2}{|c|}{ Hard to access } & \multicolumn{2}{|c|}{ Unavailable } & \multicolumn{2}{|c|}{ Not known } \\
\hline & $\overline{\mathbf{n}}$ & Percentage & $\overline{\mathbf{n}}$ & Percentage & $\overline{\mathbf{n}}$ & Percentage & $\overline{\mathbf{n}}$ & Percentage \\
\hline Plethysmographic lung volumes & 53 & 82 & 2 & 3 & 10 & 15 & 0 & 0 \\
\hline Gas transfer & 65 & 100 & 0 & 0 & 0 & 0 & 0 & 0 \\
\hline Quantitative perfusion scanning & 36 & 55 & 10 & 15 & 10 & 15 & 9 & 14 \\
\hline Walking tests & 53 & 82 & 8 & 12 & 4 & 6 & 0 & 0 \\
\hline Pulmonary rehabilitation & 60 & 92 & 4 & 6 & 1 & 2 & 0 & 0 \\
\hline
\end{tabular}


practice and that structures are put in place to ensure systematic evaluation of patients.

Acknowledgements The assistance of the British Thoracic Society membership is gratefully acknowledged.

Contributors NSH and SJ conceived the study. NSH and WM analysed the data. WM prepared the first draft and all authors contributed to and approved the final manuscript. NSH is the guarantor.

Funding The study was supported by the NIHR Biomedical Research Unit at Royal Brompton and Harefield NHS Foundation Trust and Imperial College, London.

Competing interests None.

Provenance and peer review Not commissioned; externally peer reviewed.

Data sharing statement No additional data are available.

Open Access This is an Open Access article distributed in accordance with the Creative Commons Attribution Non Commercial (CC BY-NC 3.0) license, which permits others to distribute, remix, adapt, build upon this work noncommercially, and license their derivative works on different terms, provided the original work is properly cited and the use is non-commercial. See: http:// creativecommons.org/licenses/by-nc/3.0/

\section{REFERENCES}

1. Lozano R, Naghavi M, Foreman $\mathrm{K}$, et al. Global and regional mortality from 235 causes of death for 20 age groups in 1990 and 2010: a systematic analysis for the Global Burden of Disease Study 2010. Lancet 2012;380:2095-128.

2. Nacul L, Soljak M, Samarasundera E, et al. COPD in England: a comparison of expected, model-based prevalence and observed prevalence from general practice data. J Public Health (Oxf) 2011;33:108-16.

3. Hopkinson NS, Lester-George A, Ormiston-Smith N, et al. Child uptake of smoking by area across the UK. Thorax Published Online First: 4 Dec 2013. doi:10.1136/thoraxinl-2013-204379

4. Kelly JL, Bamsey O, Smith C, et al. Health status assessment in routine clinical practice: the chronic obstructive pulmonary disease assessment test score in outpatients. Respiration 2012;84:193-9.

5. Criner GJ, Cordova F, Sternberg AL, et al. The National Emphysema Treatment Trial (NETT): part II: lessons learned about lung volume reduction surgery. Am J Respir Crit Care Med 2011;184:881-93

6. Fishman A, Martinez F, Naunheim K, et al.; National Emphysema Treatment Trial Research Group. A randomized trial comparing lung-volume-reduction surgery with medical therapy for severe emphysema. N Engl J Med 2003;348:2059-73.
7. Anthonisen NR, Skeans MA, Wise RA, et al. The effects of a smoking cessation intervention on 14.5-year mortality: a randomized clinical trial. Ann Intern Med 2005;142:233-9.

8. Nocturnal Oxygen Therapy Trial Group. Continuous or nocturnal oxygen therapy in hypoxemic chronic obstructive lung disease: a clinical trial. Ann Intern Med 1980;93:391-8.

9. Brantigan $\mathrm{OC}$, Mueller E. Surgical treatment of pulmonary emphysema. Am Surg 1957:23:789-804.

10. Ramsey SD, Sullivan SD, Kaplan RM. Cost-Effectiveness of lung volume reduction surgery. Proc Am Thorac Soc 2008;5:406-11.

11. Clark SJ, Zoumot Z, Bamsey O, et al. Surgical approaches for lung volume reduction surgery in emphysema. Clin Med 2014;14:122-7.

12. Akuthota $\mathrm{P}$, Litmanovich $\mathrm{D}$, Zutler $\mathrm{M}$, et al. An evidence-based estimate on the size of the potential patient pool for lung volume reduction surgery. Ann Thorac Surg 2012;94:205-11.

13. National Institute for Clinical Excellence. Management of chronic obstructive pulmonary disease in adults in primary and secondary care (partial update). This guideline partially updates and replaces NICE clinical guideline 12. 2010. http://guidanceniceorguk/CG101

14. Celli BR, MacNee W, Agusti A, et al. Standards for the diagnosis and treatment of patients with COPD: a summary of the ATS/ERS position paper. Eur Respir J 2004;23:932-46.

15. Shah PL, Hopkinson NS. Bronchoscopic lung volume reduction for emphysema: where next? Eur Respir J 2012;39:1287-9.

16. Oey IF, Waller DA, Bal S, et al. Lung volume reduction surgery--a comparison of the long term outcome of unilateral vs. bilateral approaches. Eur J Cardithorac Surg 2002;22:610-14.

17. Davey C, Zoumot Z, Jordan S, et al. Bronchoscopic lung volume reduction with endobronchial valves for patients with heterogeneous emphysema and intact interlobar fissures (The BeLieVeR-HIFi trial): study design and rationale. Thorax Published Online First: 24 Mar 2014. doi:10.1136/thoraxjnl-2014-205127

18. Hopkinson NS, Toma TP, Hansell DM, et al. Effect of bronchoscopic lung volume reduction on dynamic hyperinflation and exercise in emphysema. Am J Respir Crit Care Med 2005;171:453-60.

19. Hopkinson NS, Kemp SV, Toma TP, et al. Atelectasis and survival after bronchoscopic lung volume reduction for COPD. Eur Respir $J$ 2011;37:1346-51.

20. Sciurba FC, Ernst A, Herth FJF, et al. A randomized study of endobronchial valves for advanced emphysema. $N$ Engl J Med 2010;363:1233-44.

21. Shah PL, Slebos DJ, Cardoso PFG, et al. Bronchoscopic lung-volume reduction with exhale airway stents for emphysema (EASE trial): randomised, sham-controlled, multicentre trial. Lancet 2011;378:997-1005.

22. Shah PL, Zoumot Z, Singh S, et al. Endobronchial coils for the treatment of severe emphysema with hyperinflation (RESET): a randomised controlled trial. Lancet Respir Med 2013; 1:233-40.

23. Geddes D, Davies $\mathrm{M}$, Koyama $\mathrm{H}$, et al. Effect of lung-volumereduction surgery in patients with severe emphysema. N Engl J Med 2000;343:239-45. 